\title{
Modelling Tourism Demand: A Dynamic Linear AIDS Approach
}

\author{
GANG LI $^{a}$, HAIYAN SONG ${ }^{b}$, STEPHEN F. WITT $^{b}$ \\ ${ }^{a}$ School of Management, University of Surrey, Guildford GU2 7XH, United Kingdom \\ ${ }^{b}$ School of Hotel and Tourism Management, The Hong Kong Polytechnic University, \\ Hung Hom, Kowloon, Hong Kong
}

\begin{abstract}
The linear almost ideal demand system (LAIDS), in both static and dynamic forms, is examined in the context of international tourism demand. The superiority of the dynamic error correction LAIDS compared to its static counterpart is demonstrated in terms of both the acceptability of theoretical restrictions and forecasting accuracy, using a data set on the expenditure of United Kingdom tourists in twenty-two Western European countries. Both long-run and short-run demand elasticites are calculated. The expenditure elasticities show that travelling to most major destinations in Western Europe appears to be a luxury for UK tourists in the long run. The demand for travel to these destinations by UK tourists is also likely to be more price elastic in the long run than in the short run. The calculated cross-price elasticites suggest that the substitution/complementarity effects vary from destination to destination.
\end{abstract}

Keywords: Tourism demand, linear almost ideal demand system (LAIDS), error correction, demand elasticity, forecasting

\section{INTRODUCTION}

Tourism is one of the world's largest industries and has experienced rapid growth in many developed and developing nations over the last three decades. Decisionmakers in tourist destinations, especially those destinations where tourism is one of the major sources of foreign exchange, have put much effort into trying to understand the key determinants of demand for their tourism products and services in the hope of formulating and implementing appropriate tourism policies and strategies. Many empirical studies on tourism demand modelling and forecasting have been published over the period, and these studies have undoubtedly proved useful for tourism decision-makers. Detailed reviews of such studies can be found in Witt and Witt (1995), Lim (1997) and Song and Witt (2000). Most of the empirical studies are based on the single-equation approach, which suffers from specific limitations. Eadington and Redman (1991) have noted that this approach is incapable of analysing the interdependence of budget allocations to different consumer goods/services. For example, in the tourism context, the decision-making involves making a choice 
among a group of alternative destinations. A price change in one destination may influence tourists' decisions on travelling to a number of alternative destinations, as well as their expenditure in those destinations. However, lacking an explicit basis in consumer demand theory, the single-equation methodology cannot adequately model the influence of a change in tourism prices in a particular destination on the demand for other destinations. Another limitation of the single-equation approach is that it cannot be used to test the symmetry and adding-up hypotheses associated with existing demand theories.

The system of equations approach initiated by Stone (1954) overcomes these limitations. By including a group of equations (one for each consumer good) in the system and estimating them simultaneously, this approach allows one to examine how consumers choose bundles of goods in order to maximise their preference or utility with budget constraints. In the tourism context, the system of equations approach can help to analyse the impacts of relative prices in different destinations on tourists' budget allocation, i.e., which destination to visit amongst a group of alternatives. Moreover, since the cross-price elasticities associated with the estimated equations within the system have a strong theoretical base, the interrelationships between alternative destinations can be effectively evaluated. Hence it provides more reliable information for policy evaluation than the single-equation alternatives.

Although there are a number of system modelling approaches available, the almost ideal demand system (AIDS), introduced by Deaton and Muellbauer (1980), has been the most commonly used method for analysing consumer behaviour as it has considerable advantages over the others. For example, it gives an arbitrary first-order approximation to any demand system; it has a flexible functional form and does not impose any a priori restrictions on elasticities; it is easy to estimate and largely avoids the need for non-linear estimation; the restrictions of homogeneity and symmetry can be tested through linear restrictions on the parameters in the model; it is derived from the consumer cost function corresponding to price-independent generalised logarithmic (PIGLOG) consumer preferences, which permits an exact aggregation over consumers without imposing identical preferences. As far as aggregate data are concerned, a rational representative consumer is assumed to make the budgeting allocation. Therefore, although the AIDS model is developed on the basis of microeconomic theory, it can readily be generalised to the aggregate level (Edgerton et al 1996).

Although the AIDS model has received considerable attention in food demand analysis, the application of this approach to tourism demand studies is still relatively rare. A thorough literature search has identified the following publications. O'Hagan and Harrison (1984) examined American tourists' expenditure in each of 16 individual destinations, while White (1985) divided the 16 destinations into 7 regions and added a transportation equation into the demand system. Syriopoulos and Sinclair (1993) and Papatheodorou (1999) studied the demand for Mediterranean tourism by tourists from the US and various European countries. De Mello et al (2002) introduced a three-equation system to examine the expenditure allocations of UK tourists in France, Portugal and Spain. Divisekera (2003) applied AIDS models to Japan, New Zealand, UK and US demands for tourism to Australia and chosen alternative destinations. Lyssiotou (2001) specified a non-linear AIDS model to study UK demand for tourism to US, Canada and 16 European countries. The lagged dependent variable was included in the AIDS specification to capture the habit persistence effect. However, a few neighbouring destinations were aggregated in this 
study, thus the substitution and complementary effects between these individual countries were not available. All of the above studies focus on tourists' expenditure allocation to different destinations, whereas Fujii et al (1985) investigated tourists' expenditure on different consumer goods in a particular destination. Apart from Lyssiotou (2001), the specifications of AIDS models in all the other studies are static and can only give estimates of long-run demand elasticities. Although Lyssiotou (2001) incorporated the lagged dependent variable into the model specification, neither the long-run equilibrium relationship nor the short-term adjustment mechanism has been examined. Unlike all the above studies, Durbarry and Sinclair (2003) estimated an error correction AIDS in analysing the demand for tourism to Italy, Spain and the UK by French residents. This is the first attempt to use the error correction AIDS approach in tourism demand modelling and forecasting. However, the error correction AIDS models in their study omitted all the short-run explanatory variables due to their statistical insignificance. Thus, the tourists' short-run behaviour was not analysed in the study. Moreover, the forecasting performance of the dynamic AIDS was not examined in their study. The present study uses the cointegration and error correction approaches in the specification of the AIDS models, which allow a full analysis of tourists' dynamic behaviour. In other words, the responses of tourists to price and expenditure changes in the long run and short run are examined simultaneously. Furthermore, this dynamic AIDS model is expected to generate more accurate forecasts than the conventional static AIDS model, especially in the short run. This hypothesis is tested in Section 4.

\section{THE MODELS}

\section{Static LAIDS}

The static AIDS can be viewed as an extension of the Working-Leser model (Working 1943; Leser 1963) in which the budget share for good $i$ is related to the logarithms of prices and total real expenditure in the following manner:

$$
w_{i}=a_{i}+\sum_{j} \gamma_{i j} \log p_{j}+b_{i} \log (x / P)
$$

where $w_{i}$ is the budget share of the $i$ th good, $p_{j}$ is the price of the $j$ th good, $x$ is total expenditure on all goods in the system, $P$ is the aggregate price index, $x / P$ is real total expenditure, and $a_{i}, b_{i}$ and $\gamma_{i j}$ are the parameters that need to be estimated.

The aggregate price index $P$ is defined as:

$$
\log P=a_{0}+\sum_{i} \alpha_{i} \log p_{i}+\frac{1}{2} \sum_{i} \sum_{j} \gamma_{i j} \log p_{i} \log p_{j}
$$

where $a_{0}$ and $\alpha_{i}$ are the parameters that need to be estimated.

Equation (2) shows that the relationship between the price index $P$ and the prices of individual goods is non-linear, which results in a complicated non-linear estimation of the system. To linearise the relationship, Deaton and Muellbauer (1980) suggested to replace the price index $P$ with Stone's price index $\left(P^{*}\right)$ which takes the form 
$\log P^{*}=\sum_{i} w_{i} \log p_{i}$. The linear approximation of the AIDS model using this Stone's price index is termed the LAIDS. Deaton and Muellbauer (1980) found that such a linear approximation works well when the individual prices in the system are collinear. ${ }^{1}$ In tourism demand studies, the commonly used price variables are consumer price indices (CPIs), which tend to be highly corelated especially amongst the destinations in the same region such as Western Europe (see, for example, O'Hagan and Harrison 1984). Therefore, the linear approximation of AIDS should be more relevant to tourism demand.

To comply with the theoretical properties of demand theory, i.e. the budget constraint and utility maximisation, the following restrictions are imposed on the parameters in the AIDS model:

Adding-up restrictions: $\sum_{i=1}^{n} a_{i}=1, \sum_{i=1}^{n} \gamma_{i j}=0$, and $\sum_{i=1}^{n} b_{i}=0$, which allows for all budget shares to sum to unity;

Homogeneity: $\sum_{j} \gamma_{i j}=0$, which is based on the assumption that a proportional change in all prices and expenditure does not affect the quantities purchased. In other words, the consumer does not exhibit money illusion;

Symmetry: $\gamma_{i j}=\gamma_{j i}$, which takes consistency of consumers' choices into account;

Negativity: this requires the matrix of substitution effects to be negative semidefinite. One subset of the negativity restriction implies that all the compensated own price elasticities must be negative (Fujii et al 1985).

Researchers are very much interested in the demand elasticities. Due to the flexible functional form of the LAIDS model, the elasticity analysis can be easily carried out. The demand elasticities are calculated as functions of the estimated parameters, and they have standard implications. The expenditure elasticity $\left(\varepsilon_{i x}\right)$, which measures the sensitivity of demand in response to changes in expenditure, is calculated using $\varepsilon_{i x}=1+b_{i} / w_{i}$. The uncompensated own-price elasticity $\left(\varepsilon_{i i}\right)$ and cross-price elasticity $\left(\varepsilon_{i j}\right)$ measure how a change in the price of one product affects the demand for this product and other products with the total expenditure and other prices held constant. They are given by $\varepsilon_{i i}=\lambda_{i i} / w_{i}-b_{i}-1$ and $\varepsilon_{i j}=\lambda_{i j} / w_{i}-b_{i} w_{j} / w_{i}$, respectively. In the same way, the compensated price elasticities $\left(\varepsilon_{i i}^{*}\right.$ and $\left.\varepsilon_{i j}^{*}\right)$, which measure the price effects on the demand assuming the real expenditure $(x / P)$ is constant (Pyo et al 1991), are calculated as $\varepsilon_{i i}^{*}=\gamma_{i i} / w_{i}+w_{i}-1$ and $\varepsilon_{i j}^{*}=\gamma_{i j} / w_{i}+w_{j}$. In particular, the sign of the calculated $\varepsilon_{i j}^{*}$ indicates the substitutability or complementarity between the destinations under consideration (Edgerton et al 1996).

\footnotetext{
${ }^{1}$ If prices are not collinear, the use of this linear approximation may cause inconsistencies in parameter estimates. However, these inconsistencies are more serious in micro rather than aggregate data (Pashardes 1993).
} 


\section{Error correction LAIDS}

In the static LAIDS, which is also known as the long-run LAIDS model, it is implicitly assumed that there is no difference between consumers' short-run and longrun behaviour, i.e. the consumers' behaviour is always in "equilibrium". However, in reality, habit persistence, adjustment costs, imperfect information, incorrect expectations and misinterpreted real price changes often prevent consumers from adjusting their expenditure instantly to price and income changes (Anderson and Blundell 1983). Therefore, until full adjustment takes place consumers are "out of equilibrium". This is one of the reasons why most static LAIDS models cannot satisfy the theoretical restrictions (Duffy 2002). It is therefore necessary to augment the longrun equilibrium relationship with a short-run adjustment mechanism. Moreover, the static LAIDS pays no attention to the statistical properties of the data and the dynamic specification arising from time series analysis. It is well known that most economic data are non-stationary, and the presence of unit roots may invalidate the asymptotic distribution of the estimators. Therefore traditional statistics such as $t, F$ and $R^{2}$ are unreliable, and least squares estimation of the static LAIDS tends to be spurious (Granger and Newbold 1974; Chambers 1993). Furthermore, the static LAIDS is unlikely to generate accurate short-run forecasts (Chambers and Nowman 1997).

The concepts of CI and the ECM were first proposed by Engle and Granger (1987), and have been widely used by researchers and practitioners in modelling and forecasting macroeconomic activities over the last decade. The CI/ECM technique is useful for the following reasons. First, policy makers and planners are often interested in the long-run equilibrium relationship between economic variables, while marketers are mainly concerned with the short-run disequilibrium behaviour of markets and consumers. Engle and Granger (1987) showed that the long-run equilibrium relationship can be conveniently examined using the CI technique, and the ECM describes the short-run dynamic characteristics of economic activities. By transforming the $\mathrm{CI}$ regression into an ECM, both the long-run equilibrium relationship and short-run dynamics can be examined. Secondly, the spurious regression problem will not occur if the variables in the regression are cointegrated. Thirdly, the regressors in an ECM are almost orthogonal and this avoids the occurrence of multicollinearity, which may otherwise be a serious problem in econometric analysis (Syriopoulos 1995).

Before examining the CI relationship, all variables concerned need to be tested for unit roots (or orders of integration). The Augmented Dickey-Fuller (ADF) (Dickey and Fuller 1981) and Phillips-Perron (PP) (Phillips and Perron 1988) statistics can be employed for this purpose. Once the orders of integration of the variables have been identified, either the Engle and Granger (1987) two-stage approach or the Johansen (1988) maximum likelihood approach can be used to test for the CI relationship among the variables in the models (Song and Witt 2000).

Once the CI relationship between the dependent variables and the linear combination of independent variables in the long-run LAIDS is confirmed, an ECM of the LAIDS can be established and econometrically estimated with appropriate algorithms. The ECM of the LAIDS (EC-LAIDS) used in this paper follows Ray (1985) and Blanciforti et al (1986) and is given by:

$$
\Delta w_{i}=\delta_{i} \Delta w_{i t-1}+\sum_{j} \gamma_{i j} \Delta \log p_{j}+b_{i} \Delta \log \left(x / P^{*}\right)+\lambda_{i} \mu_{i t-1}
$$


where $\Delta$ refers to the difference operator, and $\mu_{i t-1}$ is the ECM term, which measures the feedback effects, and is estimated from the corresponding CI equation. $\delta_{i}$ and $\lambda_{i}$ are the parameters that need to be estimated. The restrictions in the static LAIDS are also applicable here.

Applications of the EC-LAIDS can be seen in the studies of demand for nondurable goods, food and meat products, such as Balcombe and Davis (1996), Attfield (1997), Karagiannis and Velentzas (1997), Karagiannis et al (2000) and Karagiannis and Mergos (2002). Durbarry and Sinclair (2003) introduced this approach to tourism demand analysis. However, due to insignificant coefficients, all of the short-run independent variables were deleted from their EC-LAIDS model. With such a restricted model, the different behaviours of tourists in the long-run and short-run could not be investigated. Moreover, the forecasting performance of the EC-LAIDS was ignored in their study. The current paper, therefore, fills in these gaps in the tourism literature.

\section{Model estimation and restriction tests}

Since the sum of all expenditure shares in the LAIDS model is equal to unity, the residuals variance-covariance matrix is singular. The usual solution is to delete an equation from the system and estimate the remaining equations, and then calculate the parameters in the deleted equation in accordance with the adding-up restrictions. The LAIDS model is commonly estimated using Zellner's (1962) iterative approach for seemingly unrelated regressions (SUR) in most empirical demand studies and this method is also employed in this paper.

With regard to restriction tests for homogeneity, symmetry and the joint test for both homogeneity and symmetry, the conventional methods include the Wald test, likelihood ratio test and Lagrange multiplier test. However, simulation experiments have shown that these tests have considerable bias towards rejection of the null hypothesis, especially when they are applied to large demand systems with relatively few observations (Laitinen 1978; Meinser 1979; Bera et al 1981; Balcombe and Davis 1996). Therefore, this study applies two sample-size-corrected statistics (see Appendix 1) developed by Court (1968) and Deaton (1974) to avoid the overrejection of the null hypotheses.

\section{EMPIRICAL RESULTS}

\section{The data}

Both the static and EC-LAIDS models are estimated using data on the demand for tourism to Western Europe by United Kingdom residents. There are twenty-two destinations involved: Austria, Belgium, Cyprus, Denmark, Finland, France, Germany, Gibraltar, Greece, Iceland, Irish Republic, Italy, Luxembourg, Malta, Netherlands, Norway, Portugal, Spain, Sweden, Switzerland, Turkey and former Yugoslavia. Western Europe is the most popular destination area for UK residents, with tourist spending in this region accounting for 14.8 billion pounds in 2000, which is $61.1 \%$ of the total demand. Within this area, France, Spain, Italy, Greece and Portugal are the major destinations, and tourist spending in these five countries 
accounts for more than $50 \%$ of the total in the twenty-two Western European destinations (68.6\% in 2000) (see Figure 1). Therefore, this study focuses on these five destinations, with the other seventeen aggregated to a single group as Others.

FIGURE 1

SHARES OF UK TOURIST SPENDING IN WESTERN EUROPEAN COUNTRIES (2000)

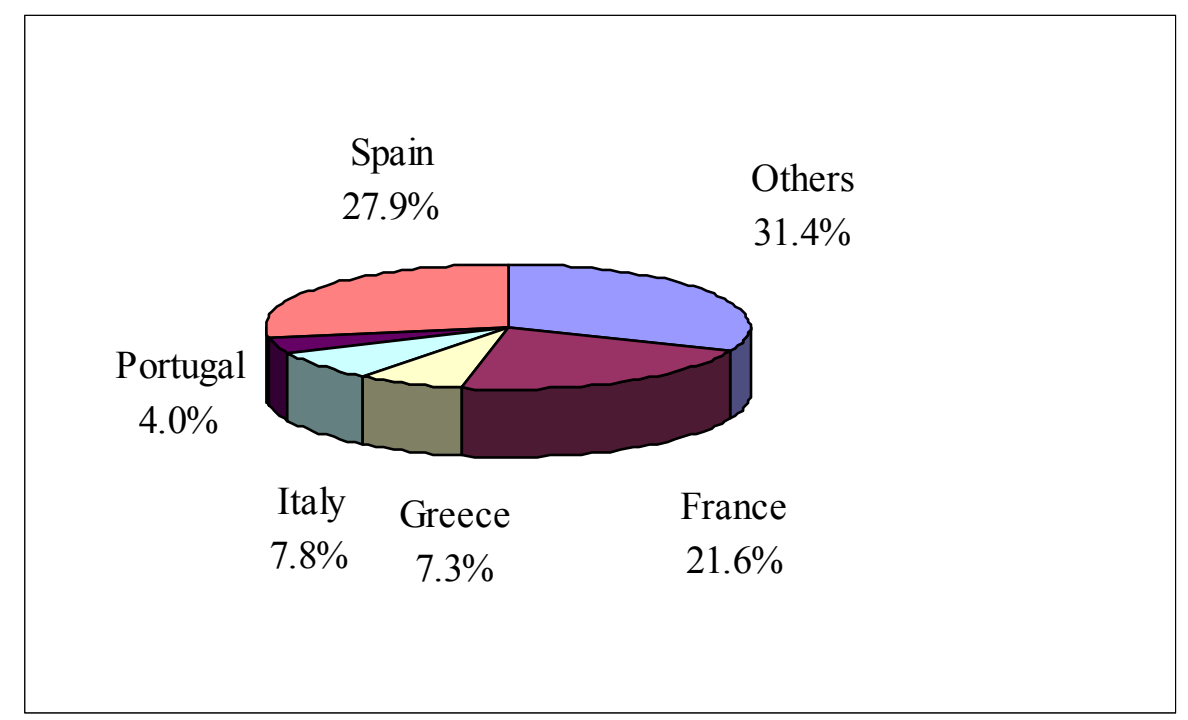

The prices employed here are relative (or effective) prices, calculated by dividing the price ${ }^{2}$ of each destination by that of the UK, adjusted by the appropriate exchange rates. The aggregated price for the Others group takes the form of Stone's price index. All the prices are normalised to unity at the point of the base year (1995). Although the expenditure data relate to all travelling purposes, they are highly correlated with the expenditure data on holidays, as pleasure travel has been dominating the tourism in the key destinations within the whole region concerned (see Table 1). Therefore, the results of the estimated LAIDS model can reflect the characteristics of the pleasure travel. The per capita expenditure is calculated and used in the model estimation in order to account for the effect of population size changes over time. In this empirical study, a three-stage budgeting process is followed. It is assumed that tourists first allocate their consumption expenditure between total tourism consumption and consumption of other goods and services. In the second stage, tourists allocate their expenditure between tourism in Western Europe and in other regions. In the last stage, tourists make their decisions among the alternative destinations in Western Europe. The LAIDS models are applied to the last stage of tourism expenditure allocation.

TABLE 1

RELATIONSHIPS BETWEEN TOURIST EXPENDITURE FOR HOLIDAYS AND FOR ALL PURPOSES (1995-2001)

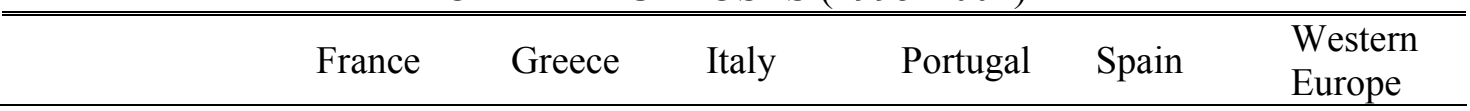

\footnotetext{
${ }^{2}$ Most empirical studies on tourism demand use CPI as a proxy for the tourism price. Econometric evidence has shown that the use of this proxy does not cause major conceptual or econometric distortions (Witt and Witt 1992).
} 


\begin{tabular}{lcccccc}
\hline $\begin{array}{l}\text { Correlation } \\
\text { Coefficient }\end{array}$ & 0.97 & 1.00 & 0.96 & 0.99 & 1.00 & 0.99 \\
\hline $\begin{array}{l}\text { Average } \\
\text { proportion (\%) }\end{array}$ & 64.3 & 91.8 & 67.3 & 88.3 & 90.4 & 70.6 \\
\hline
\end{tabular}

The data on prices, exchange rates and population are collected from the International Financial Statistical Yearbook (International Monetary Fund, various issues), and the expenditure data are collected from Travel Trends (Office for National Statistics, UK, various issues). The data set covers the period 1972-2000.

\section{Model estimation}

The ADF test for unit roots suggests that all the variables in the long-run LAIDS are I(1), and the long-run equilibrium relationships cannot be rejected by the EngleGranger approach at the $5 \%$ significance level in any case. ${ }^{3}$ Therefore, the unrestricted long-run static LAIDS models are estimated using the iterative SUR method. With regard to the dynamic LAIDS, the Engle and Granger two-step approach is employed for estimating CI regressions. The residuals from these regressions are calculated and incorporated into Equation (3), and then the unrestricted EC-LAIDS is estimated. The estimates are shown in Tables 2 and 3.

The estimated parameters $\delta_{i}$ in the EC-LAIDS are all significantly different from zero except in the Italian equation, which indicates that habit persistence plays an important role in UK tourists' decision-making process. In other words, the previous distribution of tourism expenditure in different destinations influences UK tourists' current decision on destination choice. The coefficients of error correction terms are all statistically significant at the $1 \%$ level and correctly signed, suggesting that any deviations of tourist spending from the long-run equilibrium are dynamically corrected, and hence the specification of a dynamic LAIDS is appropriate.

\footnotetext{
${ }^{3}$ The results are not presented due to space constraints, but are available from the authors upon request.
} 
TABLE 2

ESTIMATES OF THE UNRESTRICTED STATIC LAIDS

\begin{tabular}{llllll}
\hline \hline & France & Greece & Italy & Portugal & Spain \\
\hline$a_{i}$ & $\mathbf{0 . 1 7 6}$ & 0.024 & $\mathbf{0 . 1 1 6}$ & -0.001 & $\mathbf{0 . 1 4 2}$ \\
& $(10.887)$ & $(1.884)$ & $(13.889)$ & $(-0.148)$ & $(5.669)$ \\
$\gamma_{i 1}$ & -0.068 & 0.057 & 0.038 & -0.007 & 0.132 \\
& $(-1.143)$ & $(1.190)$ & $(1.249)$ & $(-0.291)$ & $(1.429)$ \\
$\gamma_{i 2}$ & $\mathbf{- 0 . 1 1 1}$ & $\mathbf{- 0 . 1 2 9}$ & $\mathbf{0 . 0 6 8}$ & 0.008 & 0.064 \\
& $(-2.104)$ & $(-3.032)$ & $(2.496)$ & $(0.360)$ & $(0.774)$ \\
$\gamma_{i 3}$ & $\mathbf{- 0 . 1 4 0}$ & $\mathbf{- 0 . 0 4 7}$ & -0.021 & $\mathbf{0 . 0 5 0}$ & $\mathbf{0 . 0 9 4}$ \\
& $(-4.624)$ & $(-1.926)$ & $(-1.314)$ & $(4.001)$ & $(1.995)$ \\
$\gamma_{i 4}$ & $\mathbf{0 . 1 2 8}$ & -0.039 & $\mathbf{- 0 . 0 4 7}$ & -0.032 & -0.108 \\
& $(3.176)$ & $(-1.196)$ & $(-2.260)$ & $(-1.963)$ & $(-1.727)$ \\
$\gamma_{i 5}$ & $\mathbf{0 . 1 8 1}$ & $\mathbf{0 . 0 7 4}$ & -0.024 & 0.020 & $\mathbf{- 0 . 2 7 0}$ \\
& $(5.305)$ & $(2.693)$ & $(-1.340)$ & $(1.463)$ & $(-5.101)$ \\
$\gamma_{i 6}$ & -0.096 & 0.047 & -0.058 & -0.019 & $\mathbf{0 . 2 2 5}$ \\
& $(-1.414)$ & $(0.862)$ & $(-1.661)$ & $(-0.678)$ & $(2.128)$ \\
$b_{i}$ & $\mathbf{0 . 0 0 7}$ & $\mathbf{0 . 0 0 9}$ & $\mathbf{- 0 . 0 0 9}$ & $\mathbf{0 . 0 0 8}$ & $\mathbf{0 . 0 2 7}$ \\
$R^{2}$ & $(1.974)$ & $(3.270)$ & $(-4.934)$ & $(5.686)$ & $(4.899)$ \\
$D W$ & 0.895 & 0.792 & 0.826 & 0.849 & 0.561 \\
& 2.24 & 1.31 & 1.66 & 1.80 & 2.21 \\
\hline
\end{tabular}

Notes: the estimates in bold type are significant at the 5\% significance level. Values in parentheses are asymptotic $t$-statistics. 
TABLE 3

ESTIMATES OF THE UNRESTRICTED EC-LAIDS

\begin{tabular}{|c|c|c|c|c|c|}
\hline & France & Greece & Italy & Portugal & Spain \\
\hline$\delta_{i}$ & $\begin{array}{l}\mathbf{0 . 1 5 6} \\
(2.330)\end{array}$ & $\begin{array}{l}\mathbf{0 . 1 7 7} \\
(2.048)\end{array}$ & $\begin{array}{l}0.125 \\
(1.631)\end{array}$ & $\begin{array}{l}\mathbf{0 . 3 4 2} \\
(2.293)\end{array}$ & $\begin{array}{l}\mathbf{0 . 3 3 1} \\
(4.905)\end{array}$ \\
\hline$\gamma_{i 1}$ & $\begin{array}{l}-0.028 \\
(-0.832)\end{array}$ & $\begin{array}{l}\mathbf{0 . 1 0 1} \\
(4.042)\end{array}$ & $\begin{array}{l}\mathbf{0 . 0 4 9} \\
(2.250)\end{array}$ & $\begin{array}{l}-0.001 \\
(-0.041)\end{array}$ & $\begin{array}{l}0.108 \\
(1.724)\end{array}$ \\
\hline$\gamma_{i 2}$ & $\begin{array}{l}-0.065 \\
(-1.725)\end{array}$ & $\begin{array}{l}-0.007 \\
(-0.236)\end{array}$ & $\begin{array}{l}0.024 \\
(1.010)\end{array}$ & $\begin{array}{l}\mathbf{0 . 0 5 4} \\
(2.457)\end{array}$ & $\begin{array}{l}-0.036 \\
(-0.506)\end{array}$ \\
\hline$\gamma_{i 3}$ & $\begin{array}{l}\mathbf{- 0 . 0 7 3} \\
(-2.514)\end{array}$ & $\begin{array}{l}-0.033 \\
(-1.246)\end{array}$ & $\begin{array}{l}-0.005 \\
(-0.293)\end{array}$ & $\begin{array}{l}\mathbf{0 . 0 6 1} \\
(3.255)\end{array}$ & $\begin{array}{l}0.063 \\
(1.156)\end{array}$ \\
\hline$\gamma_{i 4}$ & $\begin{array}{l}\mathbf{0 . 0 9 3} \\
(2.687)\end{array}$ & $\begin{array}{l}-0.058 \\
(-1.800)\end{array}$ & $\begin{array}{l}-\mathbf{- 0 . 0 5 9} \\
(-2.685)\end{array}$ & $\begin{array}{l}-0.035 \\
(-1.738)\end{array}$ & $\begin{array}{l}-0.064 \\
(-0.996)\end{array}$ \\
\hline$\gamma_{i 5}$ & $\begin{array}{l}0.029 \\
(0.910)\end{array}$ & $\begin{array}{l}0.021 \\
(0.691)\end{array}$ & $\begin{array}{l}-0.006 \\
(-0.300)\end{array}$ & $\begin{array}{l}-0.008 \\
(-0.442)\end{array}$ & $\begin{array}{l}-0.101 \\
(-1.712)\end{array}$ \\
\hline$\gamma_{i 6}$ & $\begin{array}{l}-0.050 \\
(-1.106)\end{array}$ & $\begin{array}{l}-0.009 \\
(-1.029)\end{array}$ & $\begin{array}{l}\mathbf{- 0 . 0 7 2} \\
(-2.516)\end{array}$ & $\begin{array}{l}-0.027 \\
(-1.143)\end{array}$ & $\begin{array}{l}\mathbf{0 . 2 1 1} \\
(2.615)\end{array}$ \\
\hline$b_{i}$ & $\begin{array}{l}0.007 \\
(0.633)\end{array}$ & $\begin{array}{l}0.011 \\
(1.103)\end{array}$ & $\begin{array}{l}\mathbf{- 0 . 0 1 5} \\
(-2.200)\end{array}$ & $\begin{array}{l}0.009 \\
(1.501)\end{array}$ & $\begin{array}{l}\mathbf{0 . 0 4 3} \\
(2.251)\end{array}$ \\
\hline$\lambda_{i}$ & $\begin{array}{l}-\mathbf{1 . 2 2 7} \\
(-12.278)\end{array}$ & $\begin{array}{l}\mathbf{- 1 . 0 5 3} \\
(-9.465)\end{array}$ & $\begin{array}{l}\mathbf{- 1 . 1 4 4} \\
(-9.563)\end{array}$ & $\begin{array}{l}\mathbf{- 1 . 5 1 2} \\
(-6.924)\end{array}$ & $\begin{array}{l}\mathbf{- 1 . 4 9 3} \\
(-14.660)\end{array}$ \\
\hline$R^{2}$ & 0.792 & 0.619 & 0.560 & 0.503 & 0.725 \\
\hline DW & 1.74 & 1.68 & 1.79 & 1.88 & 1.79 \\
\hline
\end{tabular}

Notes: same as Table 2.

With regard to the restriction tests, the EC-LAIDS passes all the tests at the 5\% level, while the static LAIDS fails the symmetry test and the joint tests for both homogeneity and symmetry. It indicates that ignoring the dynamic adjustment is likely to result in mis-specification of the functional form and violation of demand theory. Since the imposition of these restrictions helps to reduce the number of parameters to be estimated and increase the degrees of freedom, the homogeneity and symmetry restricted static LAIDS and EC-LAIDS are both estimated and used for elasticity analysis. The results are presented in Tables 5 and 6 . 
TABLE 4

RESTRICTION TESTS

\begin{tabular}{lllllll}
\hline \hline & \multicolumn{3}{c}{ Homogeneity } & \multicolumn{2}{c}{ Symmetry } & \multicolumn{2}{c}{ Homogeneity and symmetry } \\
& $T_{1}$ & $T_{2}$ & $T_{1}$ & $T_{2}$ & $T_{1}$ & $T_{2}$ \\
\hline Static LAIDS & $2.300^{* *}$ & $11.512^{*}$ & 3.342 & 33.421 & 3.166 & 47.483 \\
EC-LAIDS & $1.685^{* *}$ & $8.428^{* *}$ & $1.617^{* *}$ & $16.174^{* *}$ & $1.634^{* *}$ & $24.517^{* *}$ \\
\hline
\end{tabular}

Note: $*$ and $* *$ denote acceptance at the $1 \%$ and $5 \%$ significance levels, respectively.

TABLE 5

ESTIMATES OF THE HOMOGENEITY AND SYMMETRY RESTRICTED STATIC LAIDS

\begin{tabular}{llllll}
\hline \hline & France & Greece & Italy & Portugal & Spain \\
\hline$a_{i}$ & 0.230 & -0.001 & $\mathbf{0 . 1 3 3}$ & -0.002 & $\mathbf{0 . 2 1 0}$ \\
& $(1.598)$ & $(-0.076)$ & $(10.551)$ & $(-0.350)$ & $(8.640)$ \\
$\gamma_{i 1}$ & -0.057 & 0.017 & $\mathbf{- 0 . 0 3 8}$ & -0.003 & $\mathbf{0 . 1 5 5}$ \\
& $(-1.088)$ & $(0.730)$ & $(-1.660)$ & $(-0.188)$ & $(3.767)$ \\
$\gamma_{i 2}$ & 0.017 & $\mathbf{- 0 . 1 4 9}$ & -0.016 & $\mathbf{- 0 . 0 2 3}$ & 0.002 \\
& $(0.730)$ & $(-6.780)$ & $(-1.065)$ & $(-1.920)$ & $(0.097)$ \\
$\gamma_{i 3}$ & $\mathbf{- 0 . 0 3 8}$ & -0.016 & 0.003 & 0.030 & $\mathbf{- 0 . 0 4 3}$ \\
& $(-1.660)$ & $(-1.065)$ & $(0.138)$ & $(0.138)$ & $(-1.720)$ \\
$\gamma_{i 4}$ & -0.003 & $-\mathbf{0 . 0 2 3}$ & 0.030 & -0.013 & -0.001 \\
& $(-0.188)$ & $(-1.920)$ & $(0.138)$ & $(-1.250)$ & $(-0.039)$ \\
$\gamma_{i 5}$ & $\mathbf{0 . 1 5 5}$ & 0.002 & $\mathbf{- 0 . 0 4 3}$ & -0.001 & $\mathbf{- 0 . 2 0 1}$ \\
& $(3.767)$ & $(0.097)$ & $(-1.720)$ & $(-0.039)$ & $(-3.247)$ \\
$b_{i}$ & $\mathbf{0 . 0 1 6}$ & $\mathbf{0 . 0 1 4}$ & $\mathbf{- 0 . 0 0 8}$ & $\mathbf{0 . 0 0 8}$ & $\mathbf{0 . 0 1 4}$ \\
& $(4.374)$ & $(6.334)$ & $(-6.994)$ & $(2.794)$ & $(2.795)$ \\
$R^{2}$ & 0.812 & 0.716 & 0.542 & 0.810 & 0.272 \\
DW & 1.347 & 1.303 & 0.849 & 1.484 & 1.344 \\
\hline
\end{tabular}

Notes: same as Table 2. 
TABLE 6

ESTIMATES OF THE HOMOGENEITY AND SYMMETRY RESTRICTED ECLAIDS

\begin{tabular}{|c|c|c|c|c|c|}
\hline & France & Greece & Italy & Portugal & Spain \\
\hline$\delta_{i}$ & $\begin{array}{l}0.114 \\
(1.349)\end{array}$ & $\begin{array}{l}0.060 \\
(0.060)\end{array}$ & $\begin{array}{l}0.156 \\
(1.018)\end{array}$ & $\begin{array}{l}0.319 \\
(2.043)\end{array}$ & $\begin{array}{l}\mathbf{0 . 2 6 2} \\
(2.841)\end{array}$ \\
\hline$\gamma_{i 1}$ & $\begin{array}{l}0.052 \\
(1.591)\end{array}$ & $\begin{array}{l}0.034 \\
(1.555)\end{array}$ & $\begin{array}{l}-0.013 \\
(-0.727)\end{array}$ & $\begin{array}{l}-0.021 \\
(-1.359)\end{array}$ & $\begin{array}{l}\mathbf{0 . 0 9 1} \\
(2.535)\end{array}$ \\
\hline$\gamma_{i 2}$ & $\begin{array}{l}0.034 \\
(1.555)\end{array}$ & $\begin{array}{l}-\mathbf{0 . 0 7 1} \\
(-2.726)\end{array}$ & $\begin{array}{l}\mathbf{- 0 . 0 4 3} \\
(-2.516)\end{array}$ & $\begin{array}{l}0.018 \\
(1.201)\end{array}$ & $\begin{array}{l}-0.026 \\
(-0.089)\end{array}$ \\
\hline$\gamma_{i 3}$ & $\begin{array}{l}-0.013 \\
(-0.727)\end{array}$ & $\begin{array}{l}-\mathbf{0 . 0 4 3} \\
(-2.516)\end{array}$ & $\begin{array}{l}0.022 \\
(0.994)\end{array}$ & $\begin{array}{l}\mathbf{0 . 0 2 4} \\
(2.000)\end{array}$ & $\begin{array}{l}-0.008 \\
(-0.288)\end{array}$ \\
\hline$\gamma_{i 4}$ & $\begin{array}{l}-0.021 \\
(-1.359)\end{array}$ & $\begin{array}{l}0.018 \\
(1.201)\end{array}$ & $\begin{array}{l}\mathbf{0 . 0 2 4} \\
(2.000)\end{array}$ & $\begin{array}{l}-0.003 \\
(-0.231)\end{array}$ & $\begin{array}{l}-0.030 \\
(-1.652)\end{array}$ \\
\hline$\gamma_{i 5}$ & $\begin{array}{l}\mathbf{0 . 0 9 1} \\
(2.535)\end{array}$ & $\begin{array}{l}-0.026 \\
(-0.089)\end{array}$ & $\begin{array}{l}-0.008 \\
(-0.288)\end{array}$ & $\begin{array}{l}-0.030 \\
(-1.652)\end{array}$ & $\begin{array}{l}-\mathbf{0 . 1 6 0} \\
(-2.410)\end{array}$ \\
\hline$b_{i}$ & $\begin{array}{l}\mathbf{0 . 0 2 2} \\
(1.784)\end{array}$ & $\begin{array}{l}0.014 \\
(1.600)\end{array}$ & $\begin{array}{l}-0.000 \\
(-0.030)\end{array}$ & $\begin{array}{l}0.002 \\
(0.346)\end{array}$ & $\begin{array}{l}0.010 \\
(0.505)\end{array}$ \\
\hline$\lambda_{i}$ & $\begin{array}{l}\mathbf{- 1 . 0 4 8} \\
(-8.169)\end{array}$ & $\begin{array}{l}\mathbf{- 1 . 0 3 6} \\
(-8.310)\end{array}$ & $\begin{array}{l}\mathbf{- 1 . 0 1 2} \\
(-4.583)\end{array}$ & $\begin{array}{l}\mathbf{- 1 . 3 3 1} \\
(-6.182)\end{array}$ & $\begin{array}{l}-1.241 \\
(-8.565)\end{array}$ \\
\hline$R^{2}$ & 0.539 & 0.472 & 0.105 & 0.292 & 0.569 \\
\hline DW & 1.87 & 1.37 & 1.62 & 1.42 & 2.15 \\
\hline
\end{tabular}

Notes: same as Table 2.

\section{Demand elasticities}

The long-run and short-run expenditure and price elasticities are calculated in terms of the homogeneity and symmetry restricted systems, with $w_{i}$ and $w_{j}$ being replaced by the average budget shares $\bar{w}_{i}$ and $\bar{w}_{j}$, respectively. The calculated elasticites are given in Tables 7 and 8 and they are also compared with those published in previous studies. ${ }^{4}$

With respect to expenditure elasticities, the values are greater than unity no matter whether the long run or short term is concerned, the only exception being Italy, where the long-run elasticity is slightly lower than one. This suggests that travelling to the major Western European countries is generally regarded as a luxury by UK tourists. Compared with previous studies, the closest results can be found in expenditure elasticities for Spain, with three out of four cases being aligned with our conclusion.

\footnotetext{
${ }^{4}$ Since the deleted equation does not refer to any specific destination, the analysis of its elasticities is meaningless and therefore is excluded from this study.
} 
TABLE 7

EXPENDITURE ELASTICITIES: CALCULATED AND PREVIOUS LITERATURE

\begin{tabular}{lllllll}
\hline \hline & Long-run & Short-run & L1 & L2 & L3_1 & L3_2 \\
\hline France & 1.09 & 1.12 & & & 0.63 & 0.81 \\
Greece & 1.20 & 1.20 & 1.05 & 0.80 & & \\
Italy & 0.90 & 1.00 & 0.88 & 1.05 & & \\
Portugal & 1.24 & 1.05 & 1.58 & 0.04 & 0.82 & 0.95 \\
Spain & 1.06 & 1.04 & 0.90 & 1.15 & 1.20 & 1.15 \\
\hline
\end{tabular}

Notes: L1 denotes the study by Syriopoulos and Sinclair (1993), L2 by Papatheodorou (1999) and L3 by De Mello et al (2002). The whole sample is separated into 2 periods in L3, denoted as L3_1 and L3_2, respectively.

With regard to the own-price elasticities, all of the values are negative, in line with demand theory. Since there is no significant difference between the uncompensated and compensated price elasticities, only the compensated elasticities are reported.

TABLE 8

COMPENSATED OWN-PRICE ELASTICITIES: CALCULATED AND PREVIOUS LITERATURE

\begin{tabular}{lllllll}
\hline \hline & Long-run & Short-run & L1 & L2 & L3_1 & L3_2 \\
\hline France & -1.17 & -0.53 & & & -1.76 & -1.54 \\
Greece & -2.75 & -1.91 & -2.54 & -0.93 & & \\
Italy & -0.93 & -0.65 & -1.24 & -0.77 & & \\
Portugal & -1.16 & -1.05 & -2.69 & -2.85 & -2.16 & -1.71 \\
Spain & -1.52 & -1.32 & -0.72 & -0.65 & -1.26 & -1.40 \\
\hline
\end{tabular}

Notes: same as Table 7.

Comparing the long-run elasticities with the short-run elasticities, it can be seen that the long-run elasticites are generally greater than the short-run counterparts in terms of the absolute magnitude, and it is the most evident in the cases of Greece and France. This implies that in the long run tourists are more flexible in response to price changes. In the short run, due to various reasons such as information asymmetry and bounded rationality, tourists cannot fully adjust their behaviours when the price change occurs. This conclusion is consistent with demand theory. Comparing the magnitude of elasticities across destinations, UK tourists seem to be the most sensitive to price variations in Greece, while the demand for tourism to Italy appears to be the least price elastic. These results hold regardless of whether the long run or short run is considered.

As far as the cross-price elasticities are concerned, the calculated results in both the long run and short run are reported in Table 9, along with the corresponding results 
from previous studies. In order to provide robust results, two criteria are followed to select elasticities for examination, that is, the statistical significance in at least one of the long-run and short-run elasticities and consistency of signs between long-run and short-run elasticities. Compared with the previous literature, consistent substitution effects can be found in the following pairs of destinations: France and Spain (same as the results obtained by De Mello et al 2002 and Papatheodorou 1999), and Italy and Portugal (same as Papatheodorou 1999). The substitutability between the pairs of destinations is associated with their similar geographic features and cultural backgrounds. Therefore, if tourism prices in one destination (e.g. France) increase, tourists are likely to choose to go to the competing destination (e.g. Spain). However, the results show that the degree of substitution between the two destinations is different. For example, in the long run, if the prices in Spain increase by $1 \%$, the demand for France will increase by $1.15 \%$. On the other hand, if the prices in France increase by $1 \%$, the demand for Spain will increase by only $0.77 \%$. This indicates that France has gained more competitiveness over Spain in attracting UK tourists' expenditure. In addition to the substitution effect, the complementary effect is also identified between Greece and Italy, which is in line with the results of Papatheodorou (1999) and Syriopoulos and Sinclair (1993). The complementary effect occurs when UK tourists take multiple-destination trips, i.e. the voyage effect holds (see Papatheodorou 1999). A new outcome that has not been explored before refers to the substitutability between France and Greece, especially in the short run. With respect to the magnitudes of the elasticities, the values are lower than unity in terms of absolute values with only one exception. Comparing with the own-price elasticities, the cross-price elasticities show that the demand for tourism in a destination by UK residents is much less sensitive to price changes in the alternative destinations. For example, in terms of UK's long-run demand for Spanish tourism, a 1\% increase in Spanish prices would lead to a $1.52 \%$ decrease in demand for Spanish tourism, while the price changes in Greece, Italy and Portugal would not result in significant changes in the demand for Spain. It implies that other factors beyond prices may play more important roles in the competition between tourism products of different destinations.

Comparing various demand elasticities in this study with those in the previous literature, it is common to see discrepancies, which possibly result from differences in the groupings of destination countries (White 1985), estimation methods, sample periods, definitions of the variables, budget shares $\left(\bar{w}_{i} / w_{i n}\right)$ used for estimating elasticities, and so on. 
TABLE 9

COMPENSATED CROSS-PRICE ELASTICITIES: CALCULATED AND PREVIOUS LITERATURE

\begin{tabular}{|c|c|c|c|c|c|c|}
\hline & France & Greece & Italy & Portugal & Spain & \\
\hline \multirow{5}{*}{ France } & & & & & & L1 \\
\hline & & & & & & L2 \\
\hline & & & & 0.09 & 1.45 & L3_2 \\
\hline & & 0.19 & -0.16 & 0.08 & 1.15 & Static LAIDS \\
\hline & & 0.26 & 0.01 & -0.08 & 0.78 & EC-LAIDS \\
\hline \multirow{5}{*}{ Greece } & & & -0.23 & 0.56 & 1.22 & L1 \\
\hline & & & -0.98 & 1.06 & 1.16 & L2 \\
\hline & & & & & & L3_2 \\
\hline & 0.48 & & -0.03 & -0.43 & 0.23 & Static LAIDS \\
\hline & 0.65 & & -0.51 & 0.29 & -0.09 & EC-LAIDS \\
\hline \multirow{5}{*}{ Italy } & & -0.04 & & -0.83 & 0.41 & L1 \\
\hline & & & & 0.25 & 1.09 & L2 \\
\hline & & & & & & L3_2 \\
\hline & -0.35 & -0.03 & & $\mathbf{0 . 3 3}$ & -0.11 & Static LAIDS \\
\hline & 0.01 & -0.46 & & 0.34 & 0.18 & EC-LAIDS \\
\hline \multirow{5}{*}{ Portugal } & & 0.53 & -4.40 & & 4.08 & L1 \\
\hline & & & & & & L2 \\
\hline & 0.44 & & & & 1.27 & L3_2 \\
\hline & 0.35 & -0.80 & 0.69 & & -0.05 & Static LAIDS \\
\hline & -0.35 & 0.53 & 0.71 & & -0.50 & EC-LAIDS \\
\hline \multirow{5}{*}{ Spain } & & 0.20 & 0.37 & 0.70 & & L1 \\
\hline & & & & & & L2 \\
\hline & 1.73 & & & 0.23 & & L3_2 \\
\hline & 0.77 & 0.06 & -0.03 & -0.01 & & Static LAIDS \\
\hline & 0.52 & -0.02 & 0.05 & -0.07 & & EC-LAIDS \\
\hline
\end{tabular}

Notes: same as Tables 2,7 and 8.

\section{FORECASTING PERFORMANCE}

Forecasting ability is an important aspect of evaluating the performance of an econometric model. Forecasting tourism market shares and their relative changes amongst the competing destinations is very important for destination management. Many published studies on tourism forecasting show that the demand for tourism has always been growing over time. But in a demand system, when some destinations are predicted to gain more market shares, the others must suffer from the loss of their relative competitiveness. Therefore, accurate market share predictions should provide the destination government and tourism organisations with useful information for competitiveness analysis and strategy formulation. This is an additional advantage of 
the system of equations models, in particular the AIDS model, over the singleequation approach. On account of the importance of market share forecasting, it is necessary to evaluate the forecasting performance of the static and dynamic LAIDS. Since the static LAIDS does not include any lagged variables, only one-year ahead forecasts are comparable with those generated by the EC-LAIDS. Due to the failure to pass the symmetry restriction test, the static symmetry-restricted LAIDS suffers from misspecification, hence we use the unrestricted LAIDS to illustrate the difference in forecast performance between the static and dynamic systems.

Before conducting forecasting tests, it is necessary to examine parameter stability between the estimating period (1972-1996) and forecasting period (1997-2000). In this study, the statistic proposed by Anderson and Mizon (1983) (see Appendix 2) is utilised. The calculated statistics for both the static and EC-LAIDS models are less than the critical value at the 5\% significance level, indicating that there is no evidence of parameter changes over the forecasting period, so the models concerned are suitable for generating forecasts.

Both the static and dynamic unrestricted systems are re-estimated, first using the observations from 1972 up to 1996, and then one more observation being added each time, until the observations up to 1999 are used. Hence 4 one-year-ahead forecasts are obtained for each destination, and 20 for the whole system. The forecasts generated by the EC-LAIDS refer to differenced variables, which are then transformed into levels variables in order to compare the results with those from the static LAIDS. The comparisons are based on both individual equations (destinations) and the whole system (region). The mean absolute percentage error (MAPE) and the root mean square percentage error (RMSPE) are considered for both destination-specific and system-specific comparisons of forecasting accuracy (Witt and Witt, 1992). The results presented in Table 10 show that the EC-LAIDS always outperforms the static LAIDS, no matter which destination is concerned, and, moreover, the EC-LAIDS is $41.5 \%$ and $48.4 \%$ more accurate than the static LAIDS in general, judged by the MAPE and RMSPE, respectively. This result is not surprising, as the EC-LAIDS incorporates the dynamic correction mechanism, and therefore tends to capture the short-term variations more precisely. The similar result can also be found in Chambers and Nowman (1997).

TABLE 10

FORECASTING ACCURACY COMPARISON BETWEEN STATIC AND DYNAMIC UNRESTRICTED LAIDS

\begin{tabular}{|c|c|c|c|c|}
\hline \multirow{2}{*}{ Destination } & \multicolumn{2}{|c|}{$\underline{\text { Static LAIDS }}$} & \multicolumn{2}{|c|}{$\underline{\text { EC-LAIDS }}$} \\
\hline & MAPE & RMSPE & MAPE & RMSPE \\
\hline France & 0.032 & 0.051 & 0.020 & 0.022 \\
\hline Greece & 0.261 & 0.333 & 0.130 & 0.159 \\
\hline Italy & 0.105 & 0.116 & 0.063 & 0.072 \\
\hline Portugal & 0.153 & 0.171 & 0.098 & 0.099 \\
\hline Spain & 0.023 & 0.026 & 0.024 & 0.033 \\
\hline Whole system & 0.115 & 0.177 & 0.067 & 0.091 \\
\hline
\end{tabular}




\section{CONCLUDING REMARKS}

In this study, the UK demand for tourism in Western Europe has been examined using both the long-run static and the short-run EC-LAIDS models. Five destinations are considered in this study: France, Greece, Italy, Portugal and Spain. The tests for homogeneity and symmetry suggest that the dynamic version of the LAIDS satisfies demand theory well, and that the short-run adjustment should not be ignored when examining the demand for Western European tourism by UK residents. Various elasticities have been calculated and the results provide a basis for tourism policymaking in these destinations.

The calculated expenditure elasticities show that travel to most major destinations in Western Europe appears to be a luxury for UK tourists in the long run. However, a change in total tourist expenditure tends to have different influences on the demand for alternative destinations. This indicates different positions of these destinations in attracting the demand their tourism by UK residents (measured by per capita expenditure). Portugal and Greece appear to benefit more from the increase in UK tourists' expenditure in the booming period while they may suffer more from the economic recession in the UK. Hence it is important for Portugal and Greece to closely monitor the economic cycles in the UK.

As far as the own-price elasticities are concerned, UK tourists are more sensitive to price changes in the destinations in the long run than in the short term. The demand for outbound UK tourism is most sensitive to price changes in Greece and least sensitive to price changes in Italy. For the relatively price-elastic destinations, a careful control in tourism prices relative to those in neighbouring counties would benefit the growth of the tourism industry, which in turn would bring more foreign exchange earnings to the destinations. With regard to the private sectors, it should be noted that reducing prices is not necessarily the appropriate strategy to gain the competitiveness against the rivals, because it may cause retaliatory measures.

The cross-price elasticities indicate that France and Spain are likely to be substitutes in the minds of UK tourists, and also Italy and Portugal, and France and Greece. Having been aware of their strongest competitors, these destinations should keep a keen eye on their competitors' actions in tourism product promotion, and carry out quick counteracting strategies in response. To some extent, the complementary effect occurs between Italy and Greece for UK tourists. This implies that the joint promotion campaigns by both destinations can be considered in order to maximise their gains from the growing tourism flows from the UK. Comparing with other demand elasticities, the values of the cross-price elasticites are relatively small. This indicates that reducing prices does not have significant influences on attracting more tourist expenditure from the competitors. The implication for tourism businesses is that the strategies of developing new products, improving product qualities and focusing on differentiated market segments seem to be more appropriate in sustaining or enhancing their competitiveness.

With respect to forecasting tourism market shares, the dynamic LAIDS generates considerably more accurate results than the static LAIDS suggesting that the dynamic LAIDS should be used in predicting the changes in destination competitiveness. 
To conclude, this study provides a new insight into the UK tourists' dynamic behaviour in their expenditure budget allocation to different destinations. The empirical results, for the first time in the tourism context, demonstrate the superiority of the EC-LAIDS over the conventional static counterpart in terms of functional form, elasticity analysis and forecasting accuracy. Based on strong theoretical grounds, the EC-LAIDS provides more reliable information for policy evaluation than the singleequation approach. The limitation of this study is associated with lack of data availability, and the lack of disaggregated data on spending on leisure travel restricts the empirical analysis. Therefore, the results obtained should be treated with some caution.

\section{APPENDIX}

\section{Restriction tests}

$T_{1}=\frac{\operatorname{tr}\left(\Omega^{R}\right)^{-1}\left(\Omega^{R}-\Omega^{U}\right) / q}{\operatorname{tr}\left(\Omega^{R}\right)^{-1} \Omega^{U} /(n-1)(N-k)}$

$T_{2}=\frac{\operatorname{tr}\left(\Omega^{R}\right)^{-1}\left(\Omega^{R}-\Omega^{U}\right)}{\operatorname{tr}\left(\Omega^{R}\right)^{-1} \Omega^{U} /(n-1)(N-k)}$

where $\Omega^{R}$ and $\Omega^{U}$ are the estimated residual covariance matrices with and without restrictions imposed, respectively, $N$ is the number of observations, $n$ is the number of equations in the system, $k$ is the number of estimated parameters in each equation, and $q$ denotes the number of restrictions. $T_{1}$ is approximately distributed as $F(q, N-k)$ under the null hypothesis, and $T_{2}$ follows an asymptotic chi-square distribution with $q$ degrees of freedom.

\section{Parameter stability test}

$W=2\left[\left(\frac{T+m}{T}\right) \ln L_{T}+\left(\frac{T+m}{2}\right) \ln \left(\frac{T+m}{T}\right)-\ln L_{T+m}\right]$

where $T$ denotes the sample size for estimation, $m$ denotes the number of forecast periods. $L_{T}$ and $L_{T+m}$ correspond to the maximised values of the likelihood function when the systems are estimated over the sample period and the combined sample and forecast periods, respectively. $W$ is asymptotically distributed as chi-square with $m(n-1)$ degrees of freedom. 


\section{REFERENCES}

Anderson, G. and G. Mizon (1983). "Parameter Constancy Tests: Old and New." Southampton University Discussion Paper, no. 8325.

Attfield, C.L.F. (1997). "Estimating A Cointegrating Demand System," European Economic Review, 41: 61-73.

Balcombe, K. G. and J. R. Davis (1996). "An Application of Cointegration Theory in the Estimation of the Almost Ideal Demand System for Food Consumption in Bulgaria." Agricultural Economics, 15: 47-60.

Bera, A. K., R. P. Byron and C. M. Jarque (1981). "Further Evidence on Asymptotic Tests for Homogeneity and Symmetry in Large Demand Systems." Economics Letters, 8: 101105.

Blanciforti, L., R. Green and G. King (1986). U.S. Consumer Behaviour over the Post-war Period: An Almost Ideal Demand System Analysis. Monograph 40 (Giannini Foundation of Agricultural Economics, University of California).

Chambers, M. J. (1993). “Consumers' Demand in the Long Run: Some Evidence from UK Data.” Applied Economics, 25: 727-733.

Chambers, M. J. and K. B. Nowman (1997). "Forecasting with the Almost Ideal Demand System: Evidence from Some Alternative Dynamic Specifications." Applied Economics, 29: 935-943.

Court, R. H. (1968). "An Application of Demand Theory to Projecting New Zealand Retail Consumption." The Economic Review, 3: 401-411.

De Mello, M., A. Pack and M. T. Sinclair (2002). "A System of Equations Model of UK Tourism Demand in Neighbouring Countries." Applied Economics, 34: 509-521.

Deaton, A. and J. Muellbauer (1980). "An Almost Ideal Demand System." American Economic Review, 70: 312-326.

Deaton, A. (1974). "The Analysis of Consumer Demand in the United Kingdom, 1900-1970." Econometrica, 42: 341-361.

Dickey, D. A. and W. A. Fuller (1981). "Likelihood Ratio Statistics for Autoregressive Time Series with Unit Roots." Journal of the American Statistical Association, 79: 427-431.

Divisekera, S. (2003). "A Model of Demand for International Tourism." Annals of Tourism Research, 30: 31-49.

Duffy, M. (2002). "Advertising and Food, Drink and Tobacco Consumption in the United Kingdom: A Dynamic Demand System." Agricultural Economics, 1637: 1-20.

Durbarry, R. and M. T. Sinclair (2003). "Market Shares Analysis: The Case of French Tourism Demand." Annals of Tourism Research, 30: 927-941.

Eadington, W. R. and M. Redman (1991). "Economics and Tourism." Annals of Tourism Research, 18: 41-56.

Edgerton, D. L., B. Assarsson, A. Hummelmose, I. P. Laurila, K. Rickertsen and P. H. Vale (1996). The Econometrics of Demand Systems with Applications to Food Demand in the Nordic Countries. London: Kluwer Academic Publishers.

Engle, R. F. and C. W. J. Granger (1987). "Cointegration and Error Correction: Representation, Estimation and Testing." Econometrica, 55: 251-276.

Fujii, E., M. Khaled and J. Mark (1985). "An Almost Ideal Demand System for Visitor Expenditures." Journal of Transport Economics and Policy. 19: 161-171.

Granger, C. W. J. and P. Newbold (1974). "Spurious Regressions in Econometrics.” Journal of Econometrics, 2: 111-120. 
Johansen, S. (1988). “A Statistical Analysis of Cointegration Vectors.” Journal of Economic Dynamics and Control, 12: 231-254.

Karagiannis, G. and K. Velentzas (1997). "Explaining Food Consumption Patterns in Greece.” Journal of Agricultural Economics, 48: 83-92.

Karagiannis, G., S. Katranidis and K. Velentzas (2000). "An Error Correction Almost Ideal Demand System for Meat in Greece.” Agricultural Economics, 22: 29-35.

Karagiannis, G. and G. J. Mergos (2002). "Estimating Theoretically Consistent Demand Systems Using Cointegration Techniques with Application to Greek Food Data." Economics Letters, 74: 137-143.

Laitinen, K. (1978). "Why is Demand Homogeneity so often Rejected?" Economics Letters, 1: $187-191$.

Leser, C. E. V. (1963). "Forms of Engel Functions." Econometrica, 31: 694-703.

Lim, C. (1997). "An Econometric Classification and Review of International Tourism Demand Models." Tourism Economics,3: 69-81.

Lyssiotou, P. (2001). "Dynamic Analysis of British Demand for Tourism Abroad.” Empirical Economics, 15: 421-436.

Meinser, J. F. (1979). "The Sad Fate of the Asymptotic Slutsky Test for Large Systems." Economics Letters, 2: 231-233.

O'Hagan, J. W. and M. J. Harrison (1984). "Market Shares of US Tourism Expenditure in Europe: An Econometric Analysis.” Applied Economics, 16: 919-931.

Papatheodorou, A. (1999). "The Demand for International Tourism in the Mediterranean Region." Applied Economics, 31: 619-630.

Pashardes, P. (1993). "Bias in Estimation of the Almost Ideal Demand System with the Stone Index Approximation.” Economic Journal, 103: 908-916.

Phillips, P. C. B. and P. Perron (1988). "Testing for A Unit Root in Time Series Regression." Biometrica, 75: 335-346.

Pyo, S., M. Uysal and R. McLellan (1991). "A Linear Expenditure Model for Tourism Demand." Annals of Tourism Research, 31: 619-630.

Ray, R. (1985). "Specification and Time Series Estimation of Dynamic Gorman Polar Form Demand Systems." European Economic Review, 27: 357-374.

Rickertsen, K. (1998). "The Demand for Food and Beverages in Norway." Agricultural Economics, 18: 89-100.

Song, H. and S. F. Witt (2000). Tourism Demand Modelling and Forecasting: Modern Econometric Approaches. Oxford: Pergamon.

Stone, J. R. N. (1954). "Linear Expenditure Systems and Demand Analysis: An Application to the Pattern of British Demand." Economic Journal, 64: 511-527.

Syripopoulos, T. and T. Sinclair (1993). "A Dynamic Model of Demand for Mediterranean Countries." Applied Economics, 25: 1541-1552.

Syriopoulos, T. (1995). "A Dynamic Model of Demand for Mediterranean Tourism." International Review of Applied Economics, 9: 318-336.

White, K. (1985). “An International Travel Demand Model: US Travel to Western Europe.” Annals of Tourism Research, 12: 529-545.

Witt, S. F. and C. A. Witt (1992). Modelling and Forecasting Demand in Tourism. London: Academic Press.

Witt, S. F. (1995). "Forecasting Tourism Demand: A Review of Empirical Research." International Journal of Forecasting, 11: 447-475. 
Working, H. (1943). "Statistical Laws of Family Expenditure." Journal of the American Statistical Association, 38: 43-56.

Zellner, A. (1962). "An Efficient Method of Estimating Seemingly Unrelated Regressions and Test for Aggregation Bias." Journal of the American Statistical Association, 57: 348-368. 